\title{
15th Conference on Applied Surface Analysis-AOFA 15
}

\author{
Soest, 8-10 September, 2008
}

\author{
Karl-Heinz Müller • Hubert Paulus • Mark Schülke
}

Published online: 4 March 2009

(C) Springer-Verlag 2009

The biennial conference "Applied Surface Analysis" (Angewandte Oberflächenanalytik-AOFA) is an important opportunity for developers and users of surface analysis methods from universities, research institutes, and industry to meet for exchange of experience and information. Conference topics comprise the analysis and characterization of the surface and surface-near regions of materials and layer systems, chemical reactions at the surface and at internal interfaces, particle transport on surfaces and thin films, new methodological and device-related developments, and new applications of surface analytical methods.

The University of Applied Sciences of South Westphalia in the medieval town of Soest was chosen for the first time as venue of the 15th AOFA conference. It was organized by the Institut für Technologie- und Wissenstransfer TWS, the University of Applied Sciences of South Westphalia, the Deutsche Vakuum Gesellschaft DVG, and the Deutsche Physikalische Gesellschaft DPG, Fachverband Mikrosonden, in cooperation with the Österreichische Gesellschaft für Mikrochemie und Analytische Chemie (ASAC) der GÖCh, the Deutscher Arbeitskreis für Angewandte Spektroskopie (DASp) der GDCh-Fachgruppe Analytische Chemie, the European Microbeam Analysis Society EMAS, SCADEG,

\footnotetext{
K.-H. Müller $(\bowtie) \cdot H$. Paulus $(\square)$

University of Applied Sciences of South Westphalia,

Institut für Technologie- und Wissenstransfer im Kreis Soest e.V.,

Lübecker Ring 2,

59494 Soest, Germany

e-mail: mueller.k-h@fh-swf.de

e-mail: h.paulus@fh-swf.de

M. Schülke $(\square)$

University of Applied Sciences of South Westphalia,

Lübecker Ring 2,

59494 Soest, Germany

m.schuelke@fh-swf.de
}

Sektion für strukturelle und chemische Dünnschicht- und Grenzflächenanalyse der Kgl. Niederländischen Chemischen Vereinigung, the Schweizerische Arbeitsgemeinschaft Oberflächen und Grenzflächen SAOG, the Deutscher Verband für Materialforschung und -prüfung DVM and the Verein Deutscher Eisenhüttenleute VDEh.

The scientific committee, K.-H. Müller (chairman/Soest), G. Friedbacher (Wien), M. Kopnarski (Kaiserslautern), G. Marx (Chemnitz), H. Nickel (Jülich), H. Oechsner (Kaiserslautern), V. Rupertus (Mainz), D. Sommer (Duisburg), R. Szargan (Leipzig), K. Wetzig (Dresden), and Ch. Ziegler (Kaiserslautern), had again selected a number of well known scientists to cover the topics of the conference with invited talks on the above mentioned topics.

In Soest about 150 scientists from Germany, Austria, Switzerland, Hungary, Slovakia and Poland met to follow a tightly packed programme of ten invited lectures, 34 short lectures, and 28 poster contributions. Furthermore, 25 companies introduced their products and services in the field of vacuum technology and surface analysis to an interested public in a commercial exhibition.

A collection of the contributions is included in this special issue. They have undergone the regular reviewing procedures of "Analytical and Bioanalytical Chemistry", in order to comply with the high scientific standards of this journal. The editors believe that these articles illustrate current trends in surface and thin-film analysis, in particular emphasizing the status of prominent fields of application and methodological progress. Compilation of this issue would not have been possible without the referees and the expert assistance of the staff of Springer-Verlag. Their help is gratefully acknowledged.

The organizers would like to thank all commercial sponsors of the conference for their financial support: Deutsche Physikalische Gesellschaft DPG, Deutsche Vakuum Gesellschaft DVG, Gesellschaft für Akkreditierung 
und Zertifizierung GAZ, Industrie- und Handelskammer IHK Arnsberg, Sparkasse der Stadt Iserlohn, Sparkasse der Stadt Soest, Stiftung zur Förderung von Bildung, Wissenschaft und Technologie im Kreis Soest, ThyssenKrupp Steel AG, Fa. Riemer, Verein der Freunde und Förderer der Hochschulabteilung Soest, Fa. Würth.

Thanks are also extended to the companies that supported the traditional and enjoyable "Company's Night".

In the future the conference will take place alternately in Soest and Kaiserslautern. Mark your calendar: AOFA 16 will be held in Kaiserslautern in September 2010.

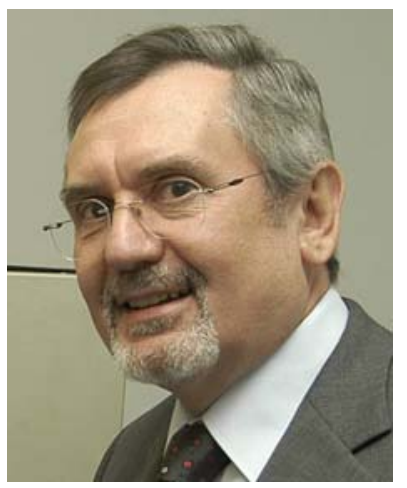

\section{Karl-Heinz Müller}

is Professor at the University of Applied Sciences of South Westphalia, Soest department, and executive director and scientific head of the Institut für Technologie- und Wissenstransfer TWS. His scientific interests are instrumental surface analysis, the storage of hydrogen in metals, and renewable energies.

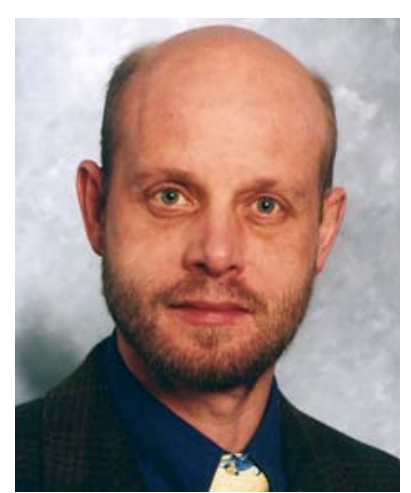

\section{Hubert Paulus}

is Head of the Surface-Analysis Laboratory of the Institut für Technologie- und Wissenstransfer TWS. His scientific interests are surface analysis (especially mass spectrometry) and the storage of hydrogen in metals.

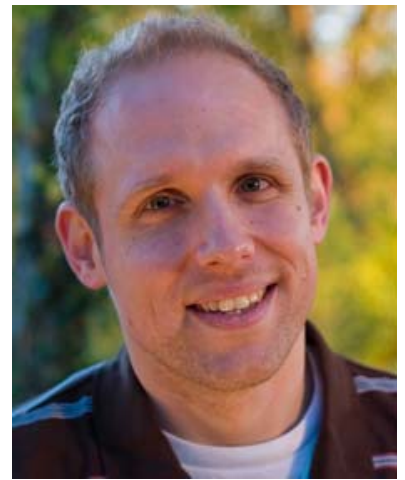

\section{Mark Schülke}

is scientific assistant at the University of Applied Sciences of South Westphalia in Soest. His research work and $\mathrm{PhD}$ thesis are focused on surface and material analysis of metal hydrides. 